\section{P-BR-131}

\section{BASIC RESEARCH}

\title{
Impact of posterior maxilla bone quality on short plateau implants success
}

Vladislav Demenko1, Igor Linetskiy², Vitalij Nesvit ${ }^{3}$, Larysa Linetska ${ }^{4}$, Oleg Yefremov

${ }^{1}$ Department of Aircraft Strength, National Aerospace University, Kharkiv, Ukraine

2 Department of Oral and Maxillofacial Surgery, $1^{\text {st }}$ Faculty of Medicine, Charles University in Prague, Prague, Czech Republic

${ }^{3}$ Department of Theoretical Mechanics, Machinery and Robotics, National Aerospace University, Kharkiv, Ukraine

4 Department of Rehabilitation Medicine, National Academy of Postgraduate Medical Education, Kharkiv, Ukraine

\section{Abstract}

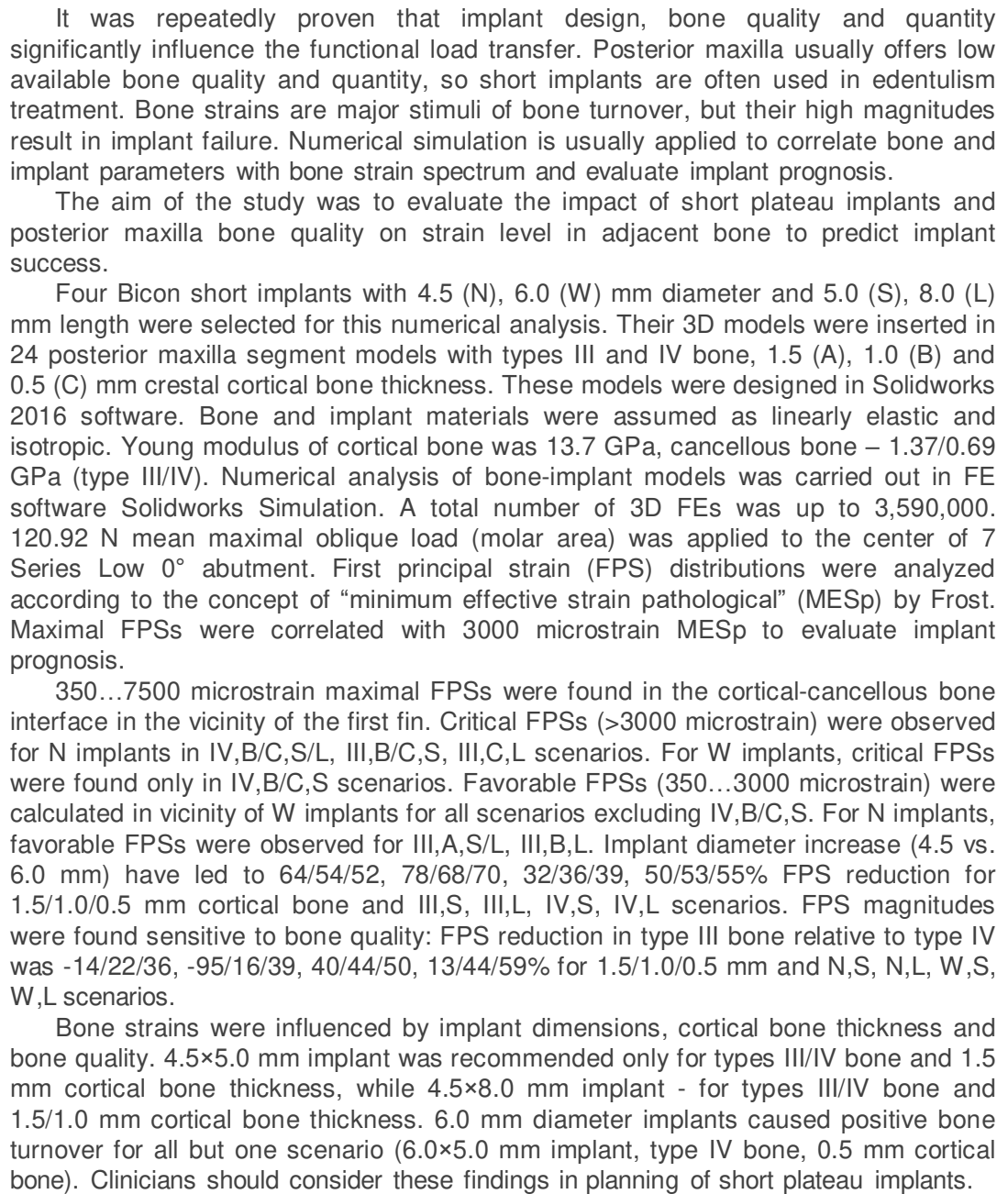

\section{Background and Aim} height and poor bone quality',2,3. Bicon screwless implant system with platea

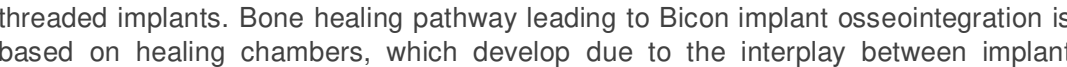

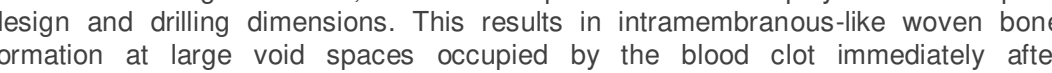
Bone strans are well-recognized simuli of bone turnover. According to Fros (actieved $b$ $\begin{array}{ll} & \\ & \end{array}$

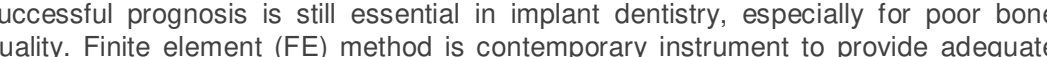

Methods and Materials

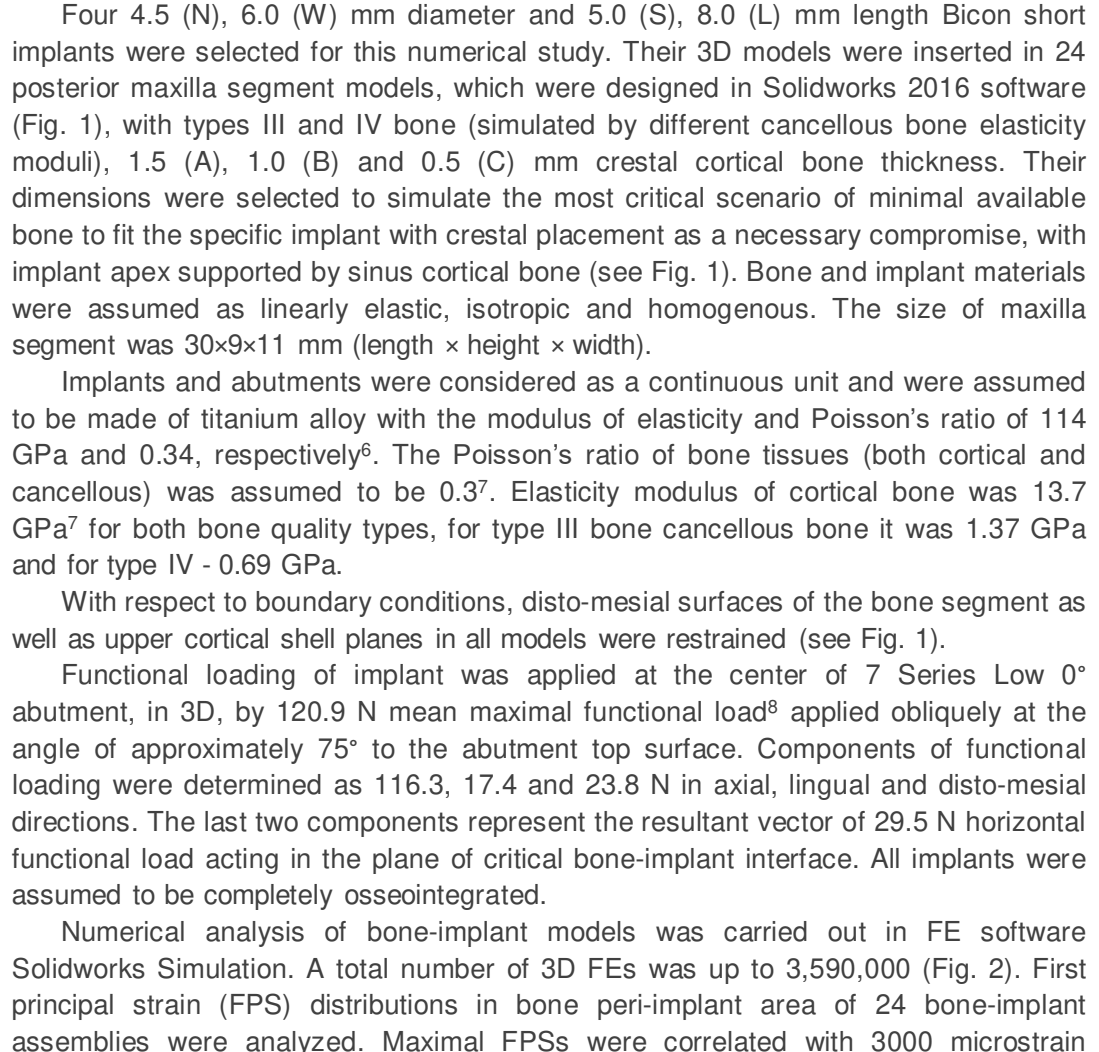

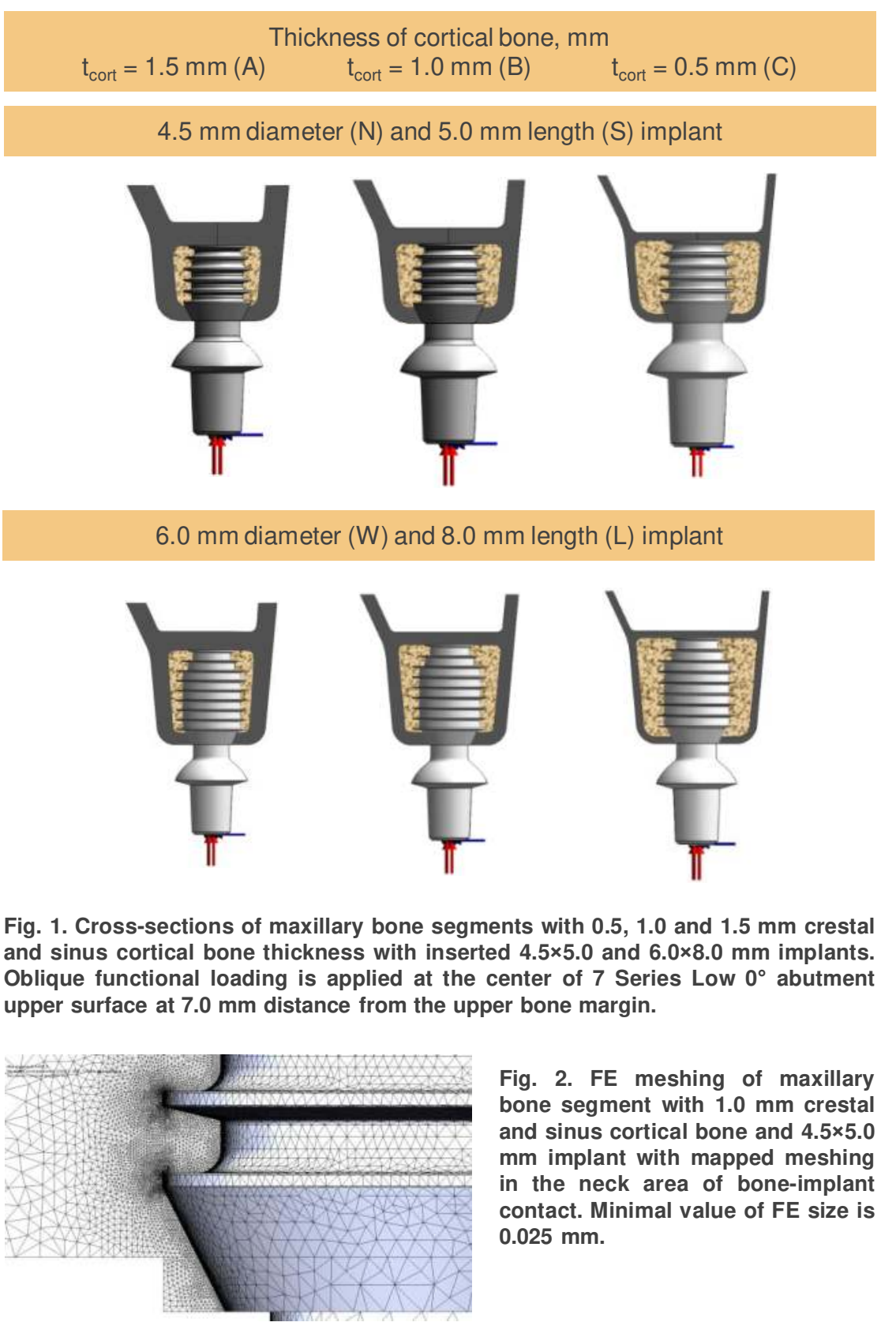

\section{Results}
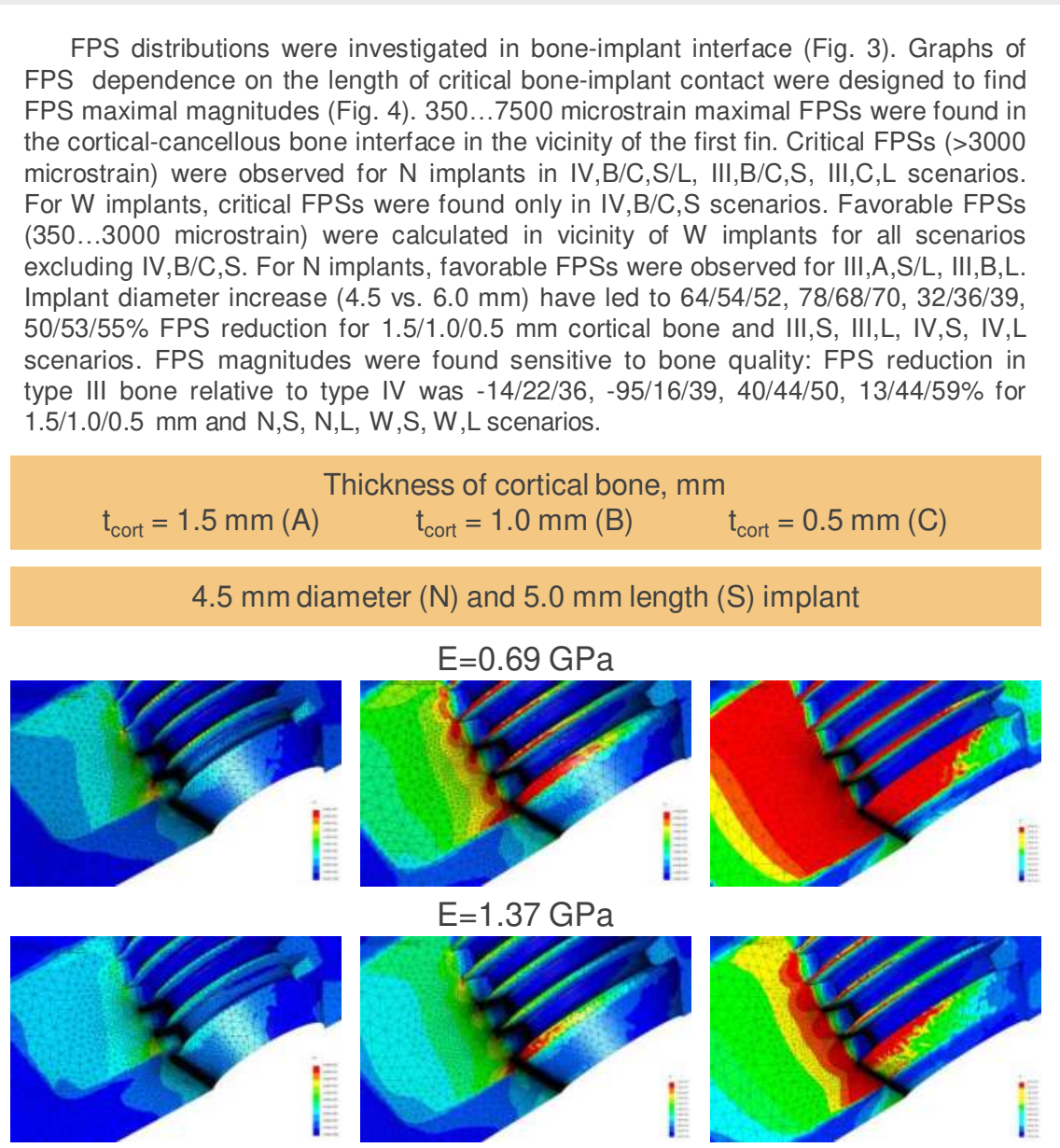

$6.0 \mathrm{~mm}$ diameter $(\mathrm{W})$ and $8.0 \mathrm{~mm}$ length $(\mathrm{L})$ implant
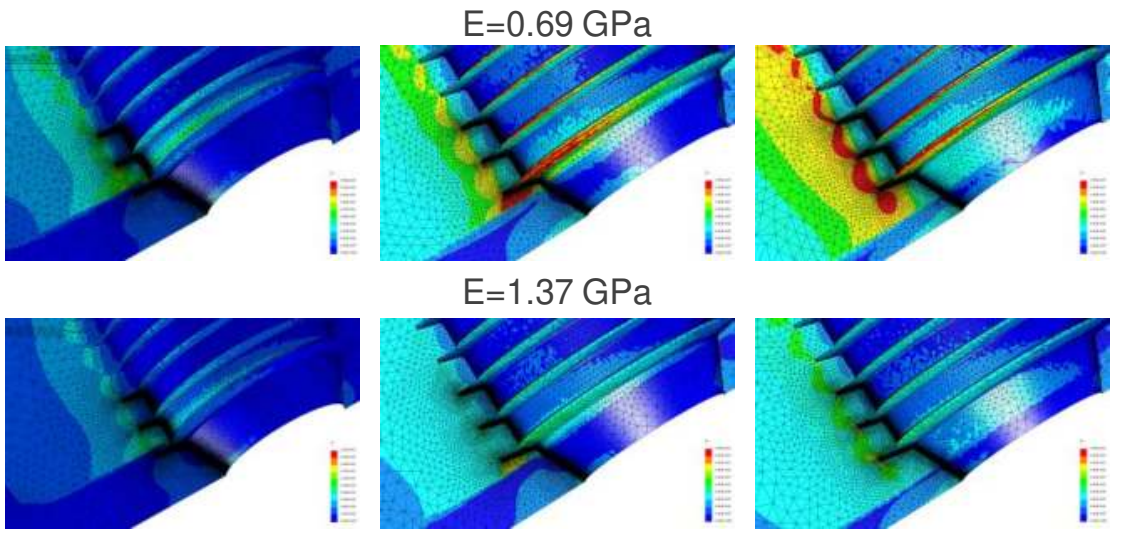

ig. 3. First principal strain distributions in the plane of
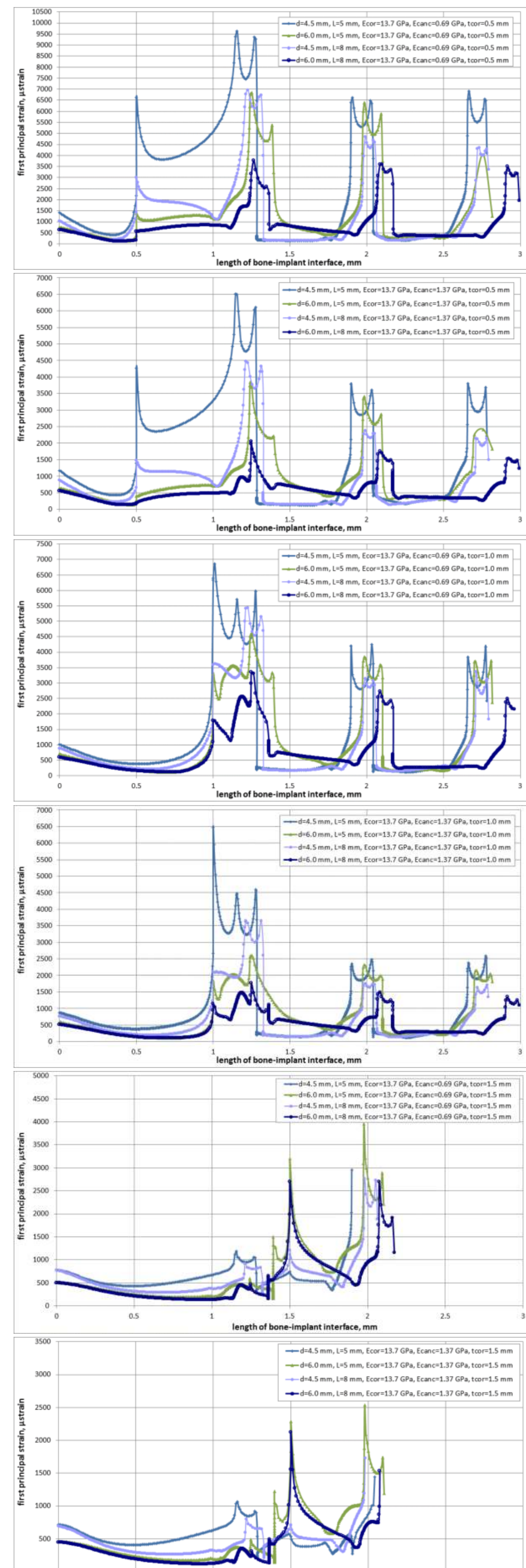

Fig. 4. First principal strain distributions along the critical line of bone-implan (E) (E.

\section{Conclusion}

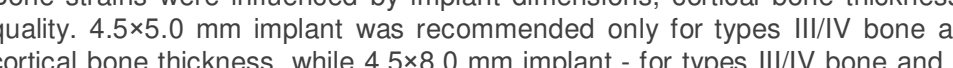
but one scenario $(6.0 \times 5.0 \mathrm{~mm}$ implant, type IV bone, $0.5 \mathrm{~mm}$ cor
hould consider these findings in planning of short plateau implants

References 